\title{
Applying qualitative approach to identify the characteristics of effective messages in eWOM communications
}

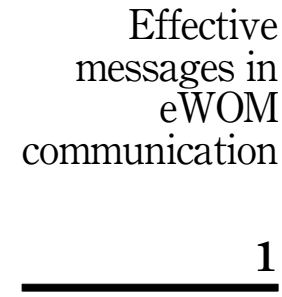

Received 14 January 2022 Revised 4 February 2022 Accepted 4 February 2022

\author{
Department of Business Management, Karaj Branch, Islamic Azad University, \\ Karaj, Iran, and \\ Milad Farzin \\ Department of Business Management, Rahedanesh Institute of Higher Education, \\ Babol, Iran and \\ Department of Business Management, Sari Branch, Islamic Azad University, \\ Sari, Iran
}

\begin{abstract}
Purpose - The present study aimed to identify the characteristics of effective messages in electronic word of mouth (eWOM) communication on social networks to be considered in the planning of eWOM strategies. For this purpose, the present study tries to identify these factors through a qualitative approach.

Design/methodology/approach - A qualitative approach based on the thematic analysis was used with semi-structured interviews and opinions of 25 experts in the field of e-marketing and e-retailing. The collected data were analyzed and coded in the MaxQDA software.

Findings - The results of the study showed the extracted seven main themes of message sender specifications, aesthetic appearance, choosing the right content, sending strategy, message usefulness, correct targeting, type of information and also 47 subthemes. These seven criteria provide a way to design the right strategies.

Research limitations/implications - Limited studies in this area were a challenge and also integrating the opinions of the interviewees due to contradictory and different views, as well as unfamiliarity with some new approaches to digital marketing, were among the limitations of the present study that managed and controlled their effects. Practical and theoretical implications for developing and planning effective eWOMs in social networks presented.

Originality/value - Understanding the way of creating appropriate features of effective and suitable messages in the planning of eWOM strategies is crucial to digital marketers. This study recommends considering the extracted features in designing effective messages.
\end{abstract}

Keywords Electronic word of mouth, Social networks sites, Message effectiveness, Thematic analysis Paper type Research paper

\section{Introduction}

With the rapid growth of social media and the widespread use of smartphones, electronic word of mouth (eWOM) has become a ubiquitous phenomenon (Zhang et al., 2017; Zamani et al., 2018). eWOM allows customers to obtain up-to-date and more realistic information. Social media networks allow users to easily publish or collect brand information at the right time and at the lowest cost (Burnasheva et al., 2019). Today, eWOM has become one of the

(C) Rosha Makvandi and Milad Farzin. Published in Management Matters. Published by Emerald Publishing Limited. This article is published under the Creative Commons Attribution (CC BY 4.0) licence. Anyone may reproduce, distribute, translate and create derivative works of this article (for both commercial and non-commercial purposes), subject to full attribution to the original publication and authors. The full terms of this licence may be seen at http://creativecommons.org/licences/by/4.0/legalcode (1)

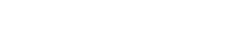


MANM

19,1

most effective tools in influencing customers' attitudes and behaviors toward brands (Sun et al., 2020). With a cascade of messages, social media users engage and exchange information through numerous channels designated as social media. By sharing personal experiences about products, online users tend to accept and use online information in their decisionmaking processes. There is a big and growing body of evidence that eWOM messages have an impact on changing consumers' attitudes and behavior (e.g. Burnasheva et al., 2019; Farzin and Fattahi, 2018). Several studies have explored the motives of applying social networking sites (SNSs) in eWOM communication and assessed significant antecedents of persuasive messages in eWOM communication (e.g. Ismagilova et al., 2019; Zhang et al., 2019). However, researchers stated that little is known about the determinants of persuasive eWOM messages when people process the information in the context of social media (Teng et al., 2014, 2017). Despite significant managerial and academic attention on eWOM, few research studies have directly tested potential determinants of eWOM messages in the social media context. Since one of the important factors in eWOM is the message itself, identifying the feature of the message is one of the key issues (Nam et al., 2020); hence, the present study focusing on the subject of "message" and its related features.

There is also heterogeneity among research findings in this area. For instance, Ismagilova et al. (2019) reported different results regarding persuasiveness of eWOM communications such as homophily of the messages' source among different studies. Farzin and Fattahi (2018) showed that the normative influence and the tie strength have no effect on eWOM communication on social networks, while previous research considered them as effective antecedents. In addition, to generalize the findings to other countries, studies have emphasized the need for research in other countries, especially developing countries (Ismagilova et al., 2019). On the other hand, some researchers have stated that one of the most important factors that increase the effectiveness of eWOM communication is the message itself and stressed the need for further research in this area (Teng et al., 2014, 2017). Moreover, many studies in the field of eWOM communication have suggested the use of qualitative research approaches such as interviews and focus groups to investigate new factors which can affect the persuasiveness of eWOM communications and gain a deep understanding and a comprehensive picture (e.g. Ismagilova et al., 2019; Farzin and Fattahi, 2018; Farzin et al., 2020b). Thus, the present study focusing on the subject of "message" and its related features discusses the characteristics of effective messages in eWOM.

The rest of this article is organized as follows. In Section 2, the literature review on eWOM communication was investigated. In Section 3, the participants, sampling procedure, data gathering process, data analysis method and trustworthiness and validity were discussed. In Section 4, the findings were presented and talk about main themes, subthemes and selective codes. In this section, a research model related to the characteristics of the message in eWOM communication was presented. In Section 5, the findings were discussed; the theoretical and practical implications are described; and the limitations and suggestions for future research were presented.

\section{Literature review}

Historically, WOM has been recognized as one of the most influential resources of information transmission (Chan and Ngai, 2011; Jalilvand et al., 2017; Le et al., 2018). WOM initially is a casual communication between people who have consumed goods or services with their own perceived evaluation, and people who are interested to experience those goods or services (Amed et al., 2019). WOM refers to sharing opinion from one consumer to another, and the conclusive stage in the consumer decision that convinces people to use the products or services and enter deep into the target audience, delivering reliable messages that are proven to change behaviors and attitudes, in offices, homes, schools, on blogs and SNSs, wherever consumers naturally talk (Jalilvand et al., 2017; Le et al., 2018). The influence of 
power of WOM on consumer decision making is well established in academic literature (Abubakar et al., 2016; Mishra et al., 2018; Sijoria et al., 2018). Referring to past literature, WOM is more effective than other marketing tools and conventional advertising media (Chan and Ngai, 2011). Therefore, it is an important area for marketing research. However, traditional WOM communications are limited by boundaries and are only effective within the network boundaries (Jalilvand et al., 2017; Seifert and Kwon, 2020).

The advent of the internet and social media has radically transformed the role of the consumer from a passive recipient of information provided by brands to a more active experiencer and creator of content. The concept of eWOM has attracted a great deal of attention in recent years due to the growth of the internet and the popularity of the e-commerce (Amed et al., 2019; Srivastava and Sivaramakrishnan, 2021). eWOM can also be considered as the extension of traditional interpersonal communications in the new age. It has attracted numerous marketing and consumer research studies, particularly regarding the motives behind exchanging eWOM and the impact of eWOM on consumption (Abubakar et al., 2016; Amed et al., 2019; Seifert and Kwon, 2020; Sijoria et al., 2018). eWOM is one of the key marketing communication tools that has been considered by both researchers and marketing practitioners (Aoki et al., 2019). Most of the studies in the field of eWOM focus on how WOM can affect its target individuals or groups and lead to changes in consumer attitudes or willingness to buy (e.g. Farzin and Fattahi, 2018; Zhang et al., 2020). Based on studies such as Kim et al. (2018), the characteristics of transmitted messages in eWOM were considered as one of the most important factors that had a significant relationship with the effectiveness of these interactions. By focusing on eWOM credibility, researchers show that message clarity and message valence were factors that affect message credibility (Moran and Muzellec, 2017). In addition, Purnawirawan et al. (2012) showed that the source credibility and the perceived usefulness of the message play a significant role in the effectiveness of eWOM. Some studies argued that the attractiveness or annoyance of eWOM had an impact on how products were evaluated (Lim and Chung, 2011).

A number of studies investigate factors that influence the persuasiveness of messages in eWOM communications. Studies showed that argument quality, source credibility, source attractiveness, source perception and source style are critical antecedents of persuasive eWOM messages (Teng et al., 2014, 2017). Farzin et al. (2020a, b) conducted a study on the dissemination of advertising messages (e.g. eWOM) on social networks by market-mavens. The results of their qualitative study showed that message salience was one of the most important factors that make users want to re-disseminate eWOMs. Ismagilova et al. (2019) stated quality, argument strength, content and valence could influence the persuasiveness of eWOM messages. Montazemi and Saremi (2014) in reviewing the effectiveness of the eWOM communication stated that features such as valence, quality, volume, sidedness, orientation and consistency were important for the effectiveness of the message. Sun et al. (2020) examined eWOM message characteristics in online consumer reviews considering message type and message valence. Srivastava and Sivaramakrishnan (2021) evaluated the effect of eWOM on brand engagement and considered features such as volume, valence and helpfulness as the dimensions of the message. Ismagilova et al. (2019) meta-analyzed the effect of eWOM communication on the intention to buy. Unlike previous research, their results showed message volume as the worst predictor for eWOM communication. Reviewing the literature in the field of eWOM message and the lack of consensus and heterogeneity of research findings, the question arises that what are the characteristics of advertising messages in eWOM communication so that marketers can formulate their strategies to apply on online platforms.

\section{Methodology}

In order to answer the research question, a qualitative and interpretive approach was taken, in which the data collection tool was semi-structured personal interviews with experts in the field of 
MANM

19,1

eWOM, and thematic analysis was used to interpret data. In this research, a qualitative inductive method is better suited to answering the research question, as the aim of this research is not to test a theory. The qualitative method approach was used to understand the multifaceted social phenomena, and aids to create the topic from the participants' points of view (Sodhi and Tang, 2018). Through its theoretical freedom, the thematic analysis provides a highly flexible approach that can be modified for the needs of many studies, providing a rich and detailed, yet complex account of data (Braun and Clarke, 2006). Farzin et al. (2020a) argued that thematic analysis is a useful method for examining the perspectives of different research participants, highlighting similarities and differences and generating unanticipated insights. The use of a qualitative approach, especially the thematic analysis method, is necessary when there are little data about the phenomenon or when the lack of a theoretical framework that is comprehensive be evident in the studies related to the subject (Braun and Clarke, 2006). There are few studies about identifying the characteristics of effective messages in eWOM communication on social networks; therefore, the lack of a comprehensive model led the researchers to provide a comprehensive model for eWOM messages. There are various methods for thematic analysis. The data analysis of this study is inspired by Braun and Clarke (2006) primary work. This method involves six subprocesses: become familiar with the data, generate initial codes, search for themes, review themes, define themes and writing the report.

The data required for this study were collected through interviews with experts involved in eWOM. Due to the qualitative nature of the research, primary participants were selected based on the purposive sampling, then sequential and snowball approach was used to continue sampling. Data saturation has been referred to as a justification for the sample size in thematic analysis, and in this study, sampling was terminated as soon as there were no additional concepts observed (Farzin et al., 2020a). Accordingly, a total of 25 experts in the field of e-marketing were interviewed. Semi-structured and open-ended interview was used as data gathering tool and was tape-recorded with the respondents' permission. To have a focused discussion, the researcher sometimes had to ask probing questions. Subsequent transcriptions were analyzed by two researchers who followed the methodological principles of thematic analysis. All interviews covered a predetermined agenda and standard questions as a means of achieving the maximum feasible level of validity across the data gathered.

In addition, we attempted to satisfy Maxwell (2004) qualitative validity (e.g. internal validity, interpretative validity and descriptive validity) through such strategies as "investigator triangulation", "participants' feedback", "low-inference description" and "data saturation". For instance, researchers by spending adequate time observing various aspects of a setting, speaking with people and developing relationships and rapport with participants attempt to satisfy "prolonged engagement". Also for "member check" and "participants' feedback", following research conduction, at each stage of analysis, the interviewer's impression was explained to the participant whereby the errors were corrected. Next, after research conduction and implementation, the results were communicated to the participants and their feedbacks were collected. In addition, the least intervention took place in the description, so the descriptive phrases were reported as they were to satisfy "low-inference description" criteria.

Based on the review method during coding and the use of a second interviewer, the reliability of the used research tool in this study was confirmed. Intercoder validity was also used to indicate the consensus between the different coders (Farzin et al., 2020a). Seven main themes and 47 subthemes were identified and coded (see Figure 1). The coding reliability of the themes among the results of the two researchers was 0.89 , which is obtained by dividing the compatible code between the two researchers into all existing codes (Farzin et al., 2020b). It should be noted that MaxQDA software was used to sort and organize the identified codes and categorize them to achieve the subthemes and main themes. For this purpose, the final interviews were entered into the software and according to the steps of the thematic analysis method, first the selective codes, then the subthemes and finally the main themes extracted based on the nature of the codes 
Effective

messages in

eWOM

communication

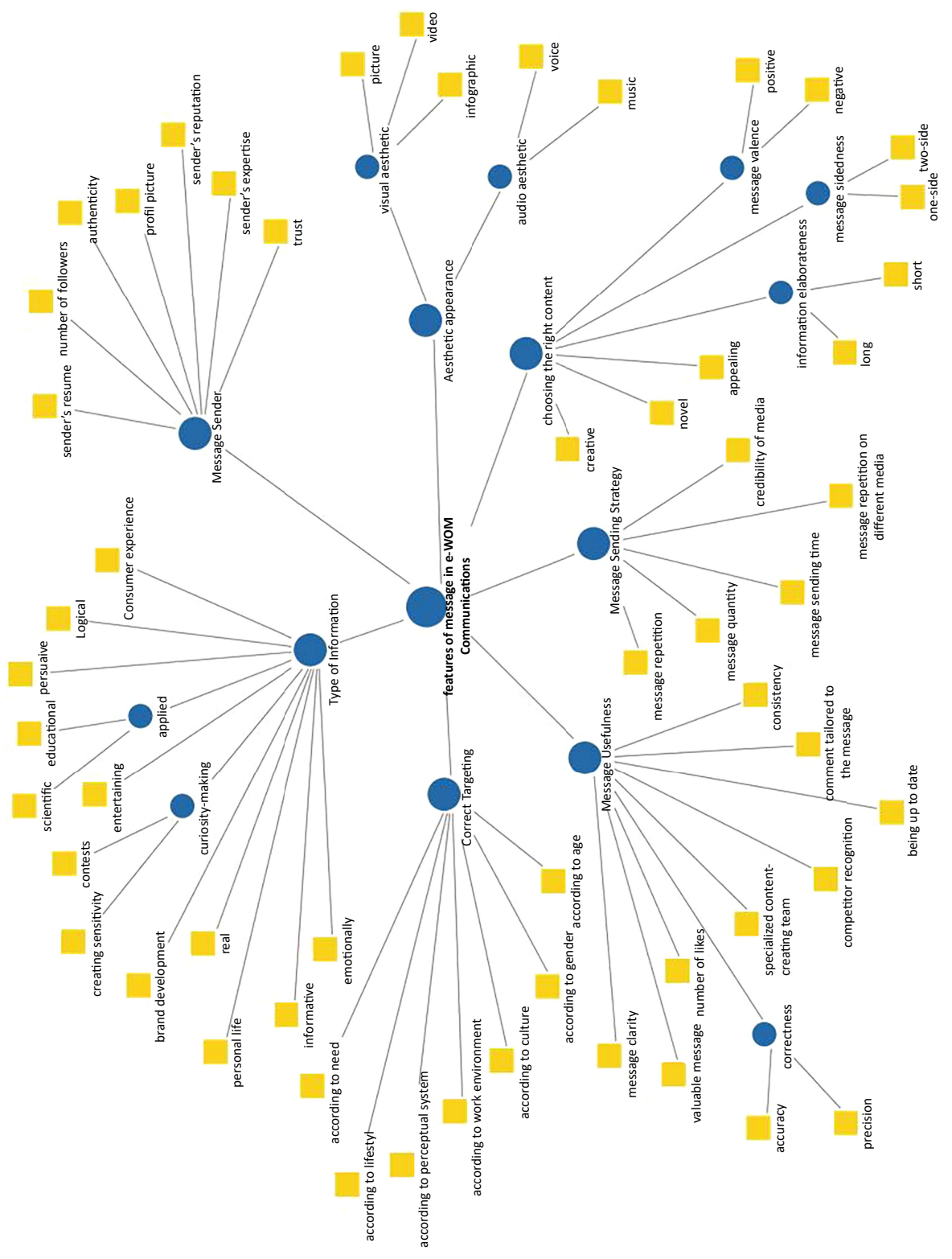

Figure 1.

Main themes, subthemes and selective codes 
MANM

19,1 from the interviews. Besides, the step of identifying the selective codes includes refining the codes several times to remove duplicate or inappropriate items.

\section{Findings}

In this study, the six phases of analysis of Braun and Clarke (2006) were used to conduct thematic analysis. For this purpose, first, the collected verbal and recorded data were transcribed into written form, and then the researcher got acquainted with the content of these interviews by studying the written texts several times. Then, based on the understanding of the data, the initial codes were generating. These open codes were used as a basis for obtaining the main codes. At this phase, 93 initial codes with a frequency of 339 codes were extracted from the interviews. The next step was to search for selective codes; the purpose of this phase is to analyze the initial code to combine them and create new themes. By discarding incomplete or less relevant codes and duplicate codes finally, 56 codes were selected.

The next phase in the thematic analysis was to reviewing the subthemes; this level involves two levels of reviewing and refining the subthemes. The first step involves reviewing at the level of the coded data extracts. In the second level, the validity of the subthemes in relation to the data set is considered. In this phase, based on two levels of reviewing and refining the subthemes, 47 subthemes were identified and extracted. Many of the selective themes appeared in the form of a subtheme. The next phase in the thematic analysis was to define and name the main themes. At this phase, the main themes defined and reviewed, and then the data inside them are analyzed. At this phase, the researcher defines seven main themes that can be explained and used in the research. Figure 1 shows the structure of the selection codes and the main themes and subthemes. Finally, using Phases 16 above in the thematic analysis, seven main themes extracted from interviews. These themes include message sender specifications, aesthetic appearance, choosing the right content, message sending strategy, message usefulness, correct targeting and type of information. Following each of these themes is examined and analyzed.

As can be seen in Figure 1, the results of theme analysis in the form of 56 selection codes (such as auditory appeal, accuracy, correctness, etc.), 47 subthemes (such as value, message direction, accuracy, etc.) and seven main themes (such as, correct targeting, message sender, etc.) are categorized as follow:

\subsection{The first main theme: message sender specifications}

The process of eWOM starts from the source of the message. It starts when the sender presents his/her attitudes and emotional states toward a product or service according to his/her experience, knowledge and feelings. The senders determine how much positive information they have about the product or service. Thus, they form their attitudes or emotional states toward the product or service in eWOM communication and distribute it through an electronic platform. Based on the interviews, the main theme of the message sender is divided into the subthemes of trust, sender resume, number of followers, authenticity, profile picture, sender reputation and expertise.

\subsection{The second main theme: type of information (content diversity)}

The other main theme is the diversity of content or type of information in the form of subthemes of consumer experience, logicality, persuasiveness, applied (educational, scientific), entertaining, curiosity (contests, sensitization), brand development, realism, personal life, informative and emotion were identified.

\subsection{The third main theme: correct targeting}

The audience is the person who responds to the eWOM (Cheung and Lee, 2012). They are looking for eWOM through various platforms via the internet. They pursue eWOM to shape 
their attitudes and emotions toward the product or service. The same eWOM could have different responses from different recipients depending on their perception, features and experience. Therefore, effective targeting and audience categorization are very important. The main themes extracted in the form of subthemes are following the needs, lifestyle, perceptual system, work environment, culture, gender and age of audiences.

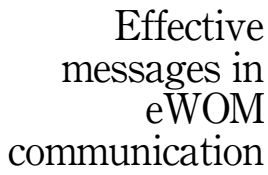

4.4 The fourth main theme: message usefulness

Another main theme extracted from the interviews is message usefulness in the form of subthemes of message clarity, creating valuable messages, number of likes, accuracy, precision, specialized team for content creating, recognizing competitors, being up to date, consistency and comments tailored to messages.

\subsection{The fifth main theme: message sending strategy}

Another main theme extracted from the interviews is the strategy of sending messages, which is in the form of subthemes of message repetition, message quantity, message sending time, repetition in different media and credibility of media. Repetition of the message is very important, i.e. the number of times the message is shared, but the repetition of the message should not be so much that it is boring for the audience.

\subsection{The sixth main theme: choosing the right content}

Choosing the appropriate content (how to present the message) is another main theme extracted from the interviews, which is in the form of subthemes of creative content, novel content, appealing content, information elaborateness (detailed, short), message sidedness, message valence (positive, negative).

\subsection{The seventh main theme: aesthetic appearance}

Visual beauty is another main theme that is explained in the form of subthemes of visual aesthetic (picture, video and info-graphics) and auditory aesthetic (voice and music).

\section{Discussion}

\subsection{Theoretical implications}

The aim of this study was to identify and better understand the message characteristics of eWOM communication due to the literature gap and heterogeneity of research results in this field. The findings of the present study shed light on the message characteristics of eWOM communication in the social network contexts. Theoretically, this study created new insights on eWOM communication by exploring the features of messages with a qualitative approach. The present study has focused on the importance of eWOM in social media as a dominant paradigm in the discussion of engaging customers with corporate marketing activities, and its effect on the important and key issue of the effectiveness of messages exchanged in the field of eWOM. Based on the results, seven main themes were identified as key factors in the effectiveness of the message in e-WOM on social networks. These main themes include $1=$ message sender, $2=$ aesthetic appearance, $3=$ choosing the right content, $4=$ message sending strategy, $5=$ message usefulness, $6=$ correct targeting and $7=$ the type of information. These main themes also include eight selective codes containing specifications of a good message: applicable, make curiosity, correctness, elaborateness, sidedness, valence, visual aesthetics and audio aesthetics.

In this section, we try to express the theoretical contributions of this study by comparing the results of the present study with other studies and highlighting its differences. Some subthemes extracted from this study existed in the research literature and some were not. The first main 
MANM

19,1

8

theme is the message sender specifications, which include trust, sender resume, number of followers, authenticity, profile photo, sender's reputation and sender's level of expertise. The literature has also emphasized variables such as trust (Ismagilova et al., 2019), sender expertise (Baber et al., 2016) and sender reputation (Castellano and Dutot, 2017) as determinants of eWOM messages, but other subthemes such as sender resume, sender authenticity, profile photo and number of followers have not been mentioned in the previous studies. In addition, the second main theme, type of information, includes subthemes of consumer experience, logicality, persuasiveness, applied (educational, scientific), entertaining, curiosity (contests, sensitization), brand development, realism, personal life, informative and emotion. The literature emphasized variables such as consumer experience (Babar et al., 2016), practicality (Alhaidari and Coughlan, 2014), entertainment (Leung et al., 2017), awareness and emotion (Alhaidari and Coughlan, 2014), persuasiveness (Chang et al., 2015) and realism and rational (Park et al., 2007) as antecedents of eWOM messages, but other subthemes such as personal life, curiosity and brand development have not been mentioned in previous studies.

The third main theme extracted in this study is correct targeting and includes subthemes of needs, lifestyle, perceptual system, work environment, culture, gender and age of audiences. Previous studies showed variables such as needs (Fan et al., 2013), gender (Alhaidari and Coughlan, 2014), age (Montazemi and Saremi, 2014) have an impact on eWOM messages, but other subthemes such as lifestyle, perceptual system, message compliance with the work environment and culture have not been mentioned. Moreover, studies revealed that creating valuable messages (Hidayanto et al., 2017;Al-Haidari and Coughlan, 2014), accuracy (Fan et al., 2013), being up to date (Cheung and Thadani, 2012) and consistency (Cheung et al., 2009) are key factors for eWOM effectiveness, but other subthemes of message usefulness (forth main theme) such as message clarity, number of likes, specialized team for content creating, recognizing competitors and comments tailored to messages have not been mentioned in the studies.

The fifth main theme is the message sending strategy and the sub-themes are message repetition, message quantity, message sending time, repetition in different media and credibility of media. The literature emphasized subthemes such as repetition or volume (Fan et al., 2013; Alhaidari and Coughlan, 2014) time of sending (Topaloglu et al., 2017), but other subthemes such as repetition in different media and the credibility of media have not been mentioned. In addition, studies showed that message valence (Topaloglu et al., 2017), information elaborateness (Cheung et al., 2008) and message sidedness (Cheung et al., 2009) are influential factors in eWOM communications, but other subthemes of choosing the appropriate content (sixth main theme) such as creative content, novel content, appealing content have not been mentioned. Finally, the seventh main theme is aesthetic appearance, which is divided into subthemes of visual aesthetic (picture, video and info-graphics), and auditory aesthetic (voice and music). Appearance features such as visual and auditory appeal and music were not found in the previous literature. However, studies such as Rittippant et al. (2009) and Danaher and Dagger (2013) emphasized the higher effectiveness of multimedia messages versus textual messages without visual elements.

\subsection{Practical implications}

This study provides useful insights for managers and marketing practitioners who seek to create and systematically develop eWOM as a promotional tool. Although some of the factors identified in the present study are beyond the control of businesses, the results suggest that eWOM can be more effective when the recipient of the message (from any source) has good perceptions about the usefulness of the message and perceive the message contents desired. In addition, what is important for the sender (whether marketers or other customers) is to choose the right content to critique or introduce a product or service, which in terms of marketing activities involves adopting appropriate strategies. These strategies include 
proper repetition of messages, the proper quantity of messages, proper timing of sending messages, sending messages from different social media and choosing authentic media.

On the other hand, if companies are looking to send their messages through intermediaries such as influencers, they must look at the sender's characteristics such as the sender's resume to customers, sender's number of followers, sender's reputation, sender's expertise and customer trust to senders. Failure to pay attention to such features will naturally reduce the effectiveness of the sent messages. In addition, the content of eWOM is another important factor that has been mentioned in studies. In order for eWOM to be as effective as possible, these messages must include some features. For example, the rationality of the message, the persuasiveness of the message and the scientific nature of the message are the three key characteristics of the effectiveness of e-WOM. Furthermore, marketers should seek to send messages that can be entertaining and, to some extent, provoke sensitivities in the recipients.

\subsection{Limitation and further research direction}

In this study, a qualitative method is used for doing research. It would be better to test the assumptions presented in this study in a quantitative study in order to generalize the results of the research to larger communities. In addition, the relationships between these themes at different levels can be measured through semi-experimental testing and manipulation of variables. The existing literature on features of eWOM messages has been very limited, and we hope to extend the research background by studying this concept in various fields. The high cost of implementing research and data collection prevented the consideration of different types of industries, social networks and respondents. And consequently, in this study, we could not take advantage of comparative studies. It is suggested to future studies examine features of eWOM messages in various industries such as tourism, healthcare, hightech vs low-tech industries. On the other hand, with regard to ethnic diversity, cross-ethnic research can be conducted to see whether ethnic stereotypes have any impact on the manifestation of such behavior among consumers or not. Furthermore, today, with the prevalence of social networks among different ages, one can investigate the impact of the cross-generational gap among individuals and see whether the age limit on individuals is meaningful or not with respect to the nature of social networks. Finally, it should be noted that although the number of interviews conducted in the qualitative section was more than the standard mentioned in the sources, and the interviews were stopped by reaching the data saturation, the more the interviews are the more you are able to increase the accuracy that is required to compare the results of the data.

\section{References}

Abubakar, A.M., Ilkan, M. and Sahin, P. (2016), "eWOM, eReferral and gender in the virtual community", Marketing Intelligence and Planning, Vol. 34 No. 5, pp. 692-710.

Alhaidari, N. and Coughlan, J. (2014), "The influence of electronic-word-of-mouth on consumer decision-making for beauty products in a Kuwaiti Women's online community", Brunel University Research Archive, Vol. 3 No. 3, pp. 34-54.

Amed, S., Mukherjee, S., Das, P. and Datta, B. (2019), "Triggers of positive eWOM: exploration with web analytics", Marketing Intelligence and Planning, Vol. 37 No. 4, pp. 433-450.

Aoki, K., Obeng, E., Borders, A.L. and Lester, D.H. (2019), "Can brand experience increase customer contribution: how to create effective sustainable touchpoints with customers?", Journal of Global Scholars of Marketing Science, Vol. 29 No. 1, pp. 51-62.

Baber, A., Thurasamy, R., Malik, M.I., Sadiq, B., Islam, S. and Sajjad, M. (2016), "Online word-of-mouth antecedents, attitude and intention-to-purchase electronic products in Pakistan", Telematics and Informatics, Vol. 33 No. 2, pp. 388-400. 
MANM

19,1

Braun, V. and Clarke, V. (2006), "Using thematic analysis in psychology", Qualitative Research in Psychology, Vol. 3 No. 2, pp. 77-101.

Burnasheva, R., Suh, Y.G. and Villalobos-Moron, K. (2019), "Sense of community and social identity effect on brand love: based on the online communities of a luxury fashion brands", Journal of Global Fashion Marketing, Vol. 10 No. 1, pp. 50-65.

Castellano, S. and Dutot, V. (2017), "Investigating the influence of E-word-of-mouth on E-reputation", International Studies of Management and Organization, Vol. 47 No. 1, pp. 42-60.

Chan, Y.Y.Y. and Ngai, E.W.T. (2011), "Conceptualising electronic word of mouth activity: an inputprocess-output perspective", Marketing Intelligence and Planning, Vol. 29 No. 5, pp. 488-516.

Chang, Y.T., Yu, H. and Lu, H.P. (2015), "Persuasive messages, popularity cohesion, and message diffusion in social media marketing", Journal of Business Research, Vol. 68 No. 4, pp. 777-782.

Cheung, C.M. and Lee, M.K. (2012), "What drives consumers to spread electronic word of mouth in online consumer-opinion platforms?”, Decision Support Systems, Vol. 53 No. 1, pp. 218-225.

Cheung, C.M. and Thadani, D.R. (2012), "The impact of electronic word-of-mouth communication: a literature analysis and integrative model", Decision Support Systems, Vol. 54 No. 1, pp. 461-470.

Cheung, C.M., Lee, M.K. and Rabjohn, N. (2008), "The impact of electronic word-of-mouth: the adoption of online opinions in online customer communities", Internet Research: Electronic Networking Applications and Policy, Vol. 18 No. 3, pp. 229-247.

Cheung, M.Y., Luo, C., Sia, C.L. and Chen, H. (2009), "Credibility of electronic word-of-mouth: informational and normative determinants of on-line consumer recommendations", International Journal of Electronic Commerce, Vol. 13 No. 4, pp. 9-38.

Danaher, P.J. and Dagger, T.S. (2013), "Comparing the relative effectiveness of advertising channels: a case study of a multimedia blitz campaign", Journal of Marketing Research, Vol. 50 No. 4, pp. 517-534.

Fan, Y.W., Miao, Y.F., Fang, Y.H. and Lin, R.Y. (2013), "Establishing the adoption of electronic wordof-mouth through consumers' perceived credibility", International Business Research, Vol. 6 No. 3 , p. 58.

Farzin, M. and Fattahi, M. (2018), "eWOM through social networking sites and impact on purchase intention and brand image in Iran", Journal of Advances in Management Research, Vol. 15 No. 2, pp. 161-183.

Farzin, M., Fattahi, M. and Yahyayi Kharkeshi, F. (2020a), Qualitative Marketing Research: Projective Techniques with Picture Drawing, LAP LAMBERT Academic Publishing, Saarbrucken.

Farzin, M., Vazifehdust, H. and Hamdi, K. (2020b), "Projective techniques for understanding cybermarket mavenism in social network sites", Revista Brasileira de Gestão de Negócios, Vol. 22 No. 3, pp. 729-749.

Hidayanto, A.N., Ovirza, M., Anggia, P., Budi, N.F.A. and Phusavat, K. (2017), "The roles of electronic word of mouth and information searching in the promotion of a new e-commerce strategy: a case of online group buying in Indonesia", Journal of Theoretical and Applied Electronic Commerce Research, Vol. 12 No. 3, pp. 69-85.

Ismagilova, E., Slade, E.L., Rana, N.P. and Dwivedi, Y.K. (2019), "The effect of electronic word of mouth communications on intention to buy: a meta-analysis", Information Systems Frontiers, Vol. 22, pp. 1203-1226.

Jalilvand, M.R., Salimipour, S., Elyasi, M. and Mohammadi, M. (2017), "Factors influencing word of mouth behaviour in the restaurant industry", Marketing Intelligence and Planning, Vol. 35 No. 1, pp. 81-110.

Kim, S., Kandampully, J. and Bilgihan, A. (2018), "The influence of eWOM communications: an application of online social network framework", Computers in Human Behavior, Vol. 80, pp. 243-254.

Le, T.D., Dobele, A.R. and Robinson, L.J. (2018), "WOM source characteristics and message quality: the receiver perspective”, Marketing Intelligence and Planning, Vol. 36 No. 4, pp. 440-454. 
Leung, X.Y., Bai, B. and Erdem, M. (2017), "Hotel social media marketing: a study on message strategy and its effectiveness", Journal of Hospitality and Tourism Technology, Vol. 8 No. 2, pp. 239-255.

Lim, B.C. and Chung, C.M. (2011), "The impact of word-of-mouth communication on attribute evaluation", Journal of Business Research, Vol. 64 No. 1, pp. 18-23.

Maxwell, J.A. (2004), "Causal explanation, qualitative research, and scientific inquiry in education", Educational Researcher, Vol. 33 No. 2, pp. 3-11.

Mishra, A., Maheswarappa, S.S., Maity, M. and Samu, S. (2018), "Teenagers' eWOM intentions: a nature vs nurture perspective", Marketing Intelligence and Planning, Vol. 36 No. 4, pp. 470-483. azemi, A.R. and Saremi, H.Q. (2014), "The effectiveness of electronic word of mouth on consumers' perceptions of adopting products/services", International Conference on Web Information, pp. 324-331.

Moran, G. and Muzellec, L. (2017), "eWOM credibility on social networking sites: a framework", Journal of Marketing Communications, Vol. 23 No. 2, pp. 149-161.

Nam, K., Baker, J., Ahmad, N. and Goo, J. (2020), "Determinants of writing positive and negative electronic word-of-mouth: empirical evidence for two types of expectation confirmation", Decision Support Systems, Vol. 129, p. 113168.

Park, D.H., Lee, J. and Han, I. (2007), "The effect of on-line consumer reviews on consumer purchasing intention: the moderating role of involvement", International Journal of Electronic Commerce, Vol. 11 No. 4, pp. 125-148.

Purnawirawan, N., De Pelsmacker, P. and Dens, N. (2012), "Balance and sequence in online reviews: how perceived usefulness affects attitudes and intentions", Journal of Interactive Marketing, Vol. 26 No. 4, pp. 244-255.

Rittippant, N., Witthayawarakul, J., Limpiti, P. and Lertdejdecha, N. (2009), "Consumers' perception of the effectiveness of short message service (SMS) and multimedia message service (MMS) as marketing tools", Proceedings of World Academy of Science: Engineering and Technology, Vol. 53, p. 815.

Seifert, C. and Kwon, W.-S. (2020), "SNS eWOM sentiment: impacts on brand value co-creation and trust", Marketing Intelligence and Planning, Vol. 38 No. 1, pp. 89-102.

Sijoria, C., Mukherjee, S. and Datta, B. (2018), "Impact of the antecedents of eWOM on CBBE", Marketing Intelligence and Planning, Vol. 36 No. 5, pp. 528-542.

Sodhi, M.S. and Tang, C.S. (2018), "Corporate social sustainability in supply chains: a thematic analysis of the literature", International Journal of Production Research, Vol. 56 Nos 1-2, pp. 882-901.

Srivastava, M. and Sivaramakrishnan, S. (2021), "The impact of eWOM on consumer brand engagement", Marketing Intelligence and Planning, Vol. 39 No. 3, pp. 469-484.

Sun, Y., Gonzalez-Jimenez, H. and Wang, S. (2020), "Examining the relationships between e-WOM, consumer ethnocentrism and brand equity", Journal of Business Research, Vol. 130 No. 4, pp. 564-573, doi: 10.1016/j.jbusres.2019.09.040.

Teng, S., Khong, K.W., Goh, W.W. and Chong, A.Y.L. (2014), "Examining the antecedents of persuasive eWOM messages in social media", Online Information Review, Vol. 38 No. 6, pp. 746-768.

Teng, S., Khong, K.W., Chong, A.Y.L. and Lin, B. (2017), "Persuasive electronic word-of-mouth messages in social media", Journal of Computer Information Systems, Vol. 57 No. 1, pp. 76-88.

Topaloglu, O., Dass, M. and Kumar, P. (2017), "Does who we are affect what we say and when? Investigating the impact of activity and connectivity on microbloggers' response to new products", Journal of Business Research, Vol. 77, pp. 23-29.

Zamani, S., Kazemi, A., Shahin, A. and Keshtiaray, N. (2018), "Exploring the factors influencing smartphone applications usage: a mixed method study", International Journal of Electronic Customer Relationship Management, Vol. 11 No. 2, pp. 105-125. 
MANM

19,1

Zhang, T.C., Omran, B.A. and Cobanoglu, C. (2017), "Generation Y's positive and negative eWOM: use of social media and mobile technology", International Journal of Contemporary Hospitality Management, Vol. 29 No. 2, pp. 732-761.

Zhang, H., Wang, Z., Chen, S. and Guo, C. (2019), "Product recommendation in online social networking communities: an empirical study of antecedents and a mediator", Information and Management, Vol. 56 No. 2, pp. 185-195.

Zhang, H., Liang, X. and Qi, C. (2020), "Investigating the impact of interpersonal closeness and social status on electronic word-of-mouth effectiveness", Journal of Business Research, Vol. 130, pp. $453-461$.

\section{Further reading}

Farzin, M., Ghaffari, R. and Fattahi, M. (2021), "The influence of social network characteristics on the purchase intention”, Business Perspectives and Research. doi: 10.1177/22785337211009661.

Mahapatra, S. and Mishra, A. (2017), "Acceptance and forwarding of electronic word of mouth", Marketing Intelligence and Planning, Vol. 35 No. 5, pp. 594-610.

\section{Corresponding author}

Milad Farzin can be contacted at: milad.farzin85@gmail.com; Milad.farzin@srbiau.ac.ir

For instructions on how to order reprints of this article, please visit our website:

www.emeraldgrouppublishing.com/licensing/reprints.htm

Or contact us for further details: permissions@emeraldinsight.com 